\title{
Hambatan dalam upaya pengembangan BIPA di luar negeri
}

\author{
Nastiti, Ayu Dwi, Lale Li Datil, Bayu Permana Sukma*) \\ Pusat Pengembangan Strategi dan Diplomasi Kebahasaan \\ *) Correspondences author: Jalan Anyar, KM. 4, Desa Tangkil, Citeureup, Bogor, 16910 \\ e-mail: bayu.permana@kemdikbud.go.id
}

\begin{abstract}
Law Number 24 Year 2009 gives a mandate to National Agency of Language Cultivation and Development, Ministry of Education and Culture through the Centre for Language Strategy and Diplomacy Development to increase function of Indonesian language as an international language. The mandate is then realized by the Centre by launching a program deploying Indonesian language teachers to 23 countries. As part of its evaluation, this research aims to identify obstacles in developing Indonesian as a Foreign Language (IFL) abroad particularly during the program from 2015 to 2017. This research used a descriptive qualitative method through document analysis. The data were obtained from 95 assignment reports by the Indonesian as a Foreign Language (IFL) teachers assigned by the Centre for Language Strategy and Diplomacy Development. The results show that there are eight aspects of obstacles found. The aspects are learning standard, students, teachers, infrastructures, institutions, environments, administration abroad, and inter-agency coordination.
\end{abstract}

Key Words: Indonesian as a Foreign Language; internationalization of Indonesian language; obstacles

This work is licensed under a Creative Commons Attribution-ShareAlike 4.0

International License.

\section{Pendahuluan}

Sejak diikrarkan sebagai bahasa nasional dalam Sumpah Pemuda 28 Oktober 1928 dan ditetapkan sebagai bahasa negara seperti tercantum pada Pasal 36 UUD 1945, bahasa Indonesia hingga saat ini telah mengalami perkembangan yang sangat pesat. Perkembangan itu telah mengantarkan bahasa Indonesia sebagai lambang jati diri bangsa dan sebagai alat pemersatu berbagai suku bangsa yang berbeda-beda latar belakang sosial, budaya, agama, dan bahasa daerahnya. Di samping itu, bahasa Indonesia juga berfungsi sebagai sarana komunikasi yang modern dalam penyelenggaraan pemerintahan, pendidikan, dan pengembangan ilmu pengetahuan serta teknologi dan seni. Fungsi tersebut semakin berkembang dengan disahkannya Undang-Undang Nomor 24 Tahun 2009 yang mengamanatkan peningkatan fungsi bahasa Indonesia sebagai bahasa internasional.

Undang-Undang Nomor 24 Tahun 2009 tentang Bendera, Bahasa, dan Lambang Negara, serta Lagu Kebangsaan pada bagian keempat Pasal 44 ayat (1) menyatakan bahwa "pemerintah meningkatkan fungsi bahasa Indonesia menjadi bahasa internasional secara bertahap, sistematis, dan berkelanjutan." Ketiga strategi peningkatan fungsi bahasa Indonesia sebagaimana tercantum pada pasal tersebut, yaitu bertahap, sistematis, dan berkelanjutan memiliki beberapa konsekuensi, sebagaimana dinyatakan Sugono (2017). Menurut Sugono (2017), bertahap maksudnya adalah bahwa sasaran penyebaran bahasa Indonesia dimulai dari cakupan wilayah yang lebih kecil dengan memprioritaskan wilayah-wilayah tertentu terlebih dahulu, seperti dimulai dari negara-negara Asia Tenggara, kemudian berlanjut ke negara-negara mitra ASEAN (Jepang, Korea Selatan, Tiongkok), Australia, India, Timur Tengah, Afrika, Uni Eropa, dan Amerika. Selain itu, bertahap juga dapat dimaknai sebagai sebuah penjenjangan. Maksudnya, penyebaran bahasa Indonesia dimulai dari jenjang atau tingkat pemula, madya, lanjut, dan profesi. Sistematis atau bersistem dimaknai bahwa upaya penginternasionalan bahasa Indonesia menganut prinsip belajar-mengajar secara komprehensif dan aplikatif dengan sasaran anakanak (sekolah dasar), remaja (sekolah menengah), pemuda/pemudi (perguruan tinggi), hingga para 
pekerja profesional. Sementara itu, berkelanjutan bermakna bahwa upaya penginternasionalan bahasa Indonesia harus dilakukan secara terus-menerus, berkesinambungan, dan konsisten.

Ketiga strategi tersebut harus ditempuh karena upaya menjadikan bahasa Indonesia berjaya di kancah internasional bukan merupakan hal yang mudah. Terdapat syarat yang harus dipenuhi oleh sebuah bahasa agar dapat menjadi bahasa internasional. Damshauser (2017) menyatakan bahwa untuk dapat menjadi menjadi bahasa dunia, sebuah bahasa harus digunakan dalam bidang diplomasi, hubungan dagang, dan penyebaran ilmu pengetahuan. Syarat-syarat tersebut juga dipertegas oleh Phillipson (2008) yang menyatakan bahwa bahasa Inggris dapat menjadi bahasa internasional saat ini karena bahasa tersebut merupakan bahasa penghubung utama di bidang politik, perdagangan, ilmu pengetahuan, teknologi, aliansi militer, hiburan, dan pariwisata. Oleh karena itu, dalam rangka memenuhi syarat-syarat tersebut, terutama syarat nomor (1), (2), dan (3), banyak upaya yang harus ditempuh, salah satunya melalui pengiriman tenaga pengajar bahasa Indonesia ke luar negeri.

Sebagaimana diatur dalam Peraturan Pemerintah Nomor 57 Tahun 2014 dan Peraturan Menteri Pendidikan dan Kebudayaan Nomor 11 Tahun 2015, tugas dan fungsi peningkatan bahasa Indonesia menjadi bahasa internasional dijalankan oleh sebuah lembaga kebahasaan, dalam hal ini oleh Badan Pengembangan dan Pembinaan Bahasa, Kementerian Pendidikan dan Kebudayaan melalui Pusat Pengembangan Strategi dan Diplomasi Kebahasaan (PPSDK). Sejak tahun 2015, PPSDK telah menjalankan fungsi tersebut melalui pengiriman tenaga pengajar BIPA ke luar negeri. Tercatat hingga saat ini bahasa Indonesia telah diajarkan di 26 negara dengan jumlah lembaga tidak kurang dari 133 lembaga, yang terdiri atas perguruan tinggi, pusat-pusat kebudayaan asing, KBRI, dan lembaga-lembaga kursus.

Program ini berjalan baik dan mendapatkan sambutan yang baik pula dari berbagai pihak, baik perwakilan Republik Indonesia, lembaga penyelenggara BIPA, maupun pemelajar BIPA di negara sasaran. Namun demikian sebagaimana lazimnya pelaksanaan sebuah program, beberapa hambatan atau kekurangan dalam program pengajaran BIPA di luar negeri masih ditemukan.

Agar program tersebut dapat berjalan semakin baik dan tepat sasaran, diperlukan evaluasi yang berpijak pada hasil kajian atau penelitian. Namun sayangnya penelitian yang mengkaji hambatan pengembangan BIPA, khususnya program pengiriman tenaga pengajar BIPA ke luar negeri oleh PPSDK belum banyak dilakukan, bahkan dapat dikatakan belum ada. Atas dasar kebutuhan tersebut penelitian ini dilakukan untuk memetakan berbagai hambatan yang terdapat di setiap negara serta mengidentifikasi jumlah pengajar yang mengalami hambatan-hambatan tersebut. Hambatan yang dibahas dalam penelitian ini tidak hanya mencakup hambatan dalam penyelenggaraan BIPA, namun juga hambatan dalam upaya pengembangan BIPA di luar negeri secara umum. Hasil penelitian ini akan sangat berguna sebagai bahan rekomendasi dan penyusunan kebijakan untuk menentukan arah dan langkah penginternasionalan bahasa Indonesia di masa yang akan datang.

\section{Metode Penelitian}

Penelitian ini menggunakan pendekatan deskriptif kualitatif, sebuah metode penelitian yang memosisikan peneliti sebagai instrumen kunci (Sugiyono, 2010). Data yang digunakan adalah data sekunder berupa laporan yang disusun oleh para pengajar BIPA di luar negeri. Laporan yang dianalisis berjumlah 95 laporan pengajar BIPA dari 23 negara tempat dilaksanakan pengajaran, yaitu Malaysia, Mesir, Timor Leste, Laos, Tunisia, Thailand, Prancis, Rusia, Filipina, Papua Nugini, India, Uzbekistan, Australia, Amerika, Myanmar, Singapura, Italia, Kamboja, Vietnam, Inggris, Jerman, Finlandia, dan Jepang. Laporan-laporan terkait pengajaran BIPA yang dianalisis tersebut merupakan laporan pengajar masa tugas tahun 2015 sampai dengan tahun 2017.

Data-data yang diperoleh dari laporan tersebut kemudian dianalisis dengan pendekatan tematik, yaitu mengidentifikasi tema-tema secara terpola dalam suatu fenomena (Maguire \& Delahunt, 2017). Dalam penelitian ini, fenomena yang dikaji adalah hambatan-hambatan yang dialami dalam upaya pengembangan BIPA di luar negeri. Setelah dianalisis, data kemudian disajikan dalam bentuk grafik dan uraian singkat. 


\section{Hasil dan Pembahasan}

Proses pembelajaran BIPA di luar negeri bertujuan untuk menyebarkan dan menginternasionalkan bahasa Indonesia agar dikenal dunia sehingga jumlah penutur nonIndonesia di kawasan ASEAN yang menggunakan bahasa Indonesia mencapai 2500 orang pada 2019 (Rencana Strategis PPSDK 2015 - 2019).

Dalam pelaksanaannya, pembelajaran BIPA menemui beberapa hambatan. Hambatanhambatan tersebut dialami oleh para pengajar BIPA selama masa penugasan di luar negeri. Secara umum, hambatan yang dialami pengajar di 23 negara dapat diklasifikasikan menjadi delapan aspek, yaitu hambatan dalam aspek standar pembelajaran, pemelajar, pengajar, prasarana dan sarana, lembaga, lingkungan, administrasi di luar negeri, dan koordinasi.

Hambatan dari aspek standar pembelajaran adalah kesulitan-kesulitan yang menjadi penghambat dalam upaya pengembangan BIPA terkait dengan proses pembelajaran BIPA, termasuk kurikulum dan silabus, kualitas dan kuantitas bahan ajar, jumlah pengajar BIPA, dan alokasi waktu. Hambatan dari aspek pemelajar adalah kesulitan-kesulitan yang menjadi penghambat dalam upaya pengembangan BIPA yang berasal dari pemelajar misalnya tingkat kehadiran, motivasi, dan minat pemelajar. Hambatan dari aspek pengajar adalah kesulitan-kesulitan yang menjadi penghambat dalam upaya pengembangan BIPA misalnya kemampuan bahasa asing negera sasaran. Hambatan aspek prasarana dan sarana adalah kesulitan-kesulitan yang menjadi penghambat dalam upaya pengembangan BIPA termasuk ruang kelas, media pembelajaran, jaringan internet, dan listrik. Hambatan aspek lembaga sasaran adalah kesulitankesulitan yang menjadi penghambat dalam upaya pengembangan BIPA di luar negeri yang disebabkan oleh kebijakan-kebijakan dikeluarkan oleh lembaga sasaran BIPA dan lokasi lembaga. Hambatan dari aspek lingkungan adalah kesulitan- kesulitan yang menjadi penghambat dalam upaya pengembangan BIPA yang berasal dari luar (eksternal) yang dialami oleh para pengajar BIPA, seperti tempat tinggal, cuaca, keadaan alam, dan geografis negara tempat penugasan. Hambatan dalam aspek administrasi di luar negeri adalah kesulitan-kesulitan yang menjadi penghambat dalam upaya pengembangan BIPA termasuk visa dan izin tinggal di negara tempat penugasan. Hambatan dalam aspek koordinasi adalah kesulitan-kesulitan yang menjadi penghambat dalam upaya pengembangan BIPA yang terkait dengan kerjasama dan koordinasi yang dilakukan oleh seluruh lembaga yang terkait dan bertanggung jawab serta memiliki andil dalam pelaksanaan program pengajaran BIPA. Ilustrasi mengenai jenis hambatan yang dialami oleh para pengajar BIPA di 23 negara penugasan beserta jumlahnya ditunjukkan oleh Gambar 1. 


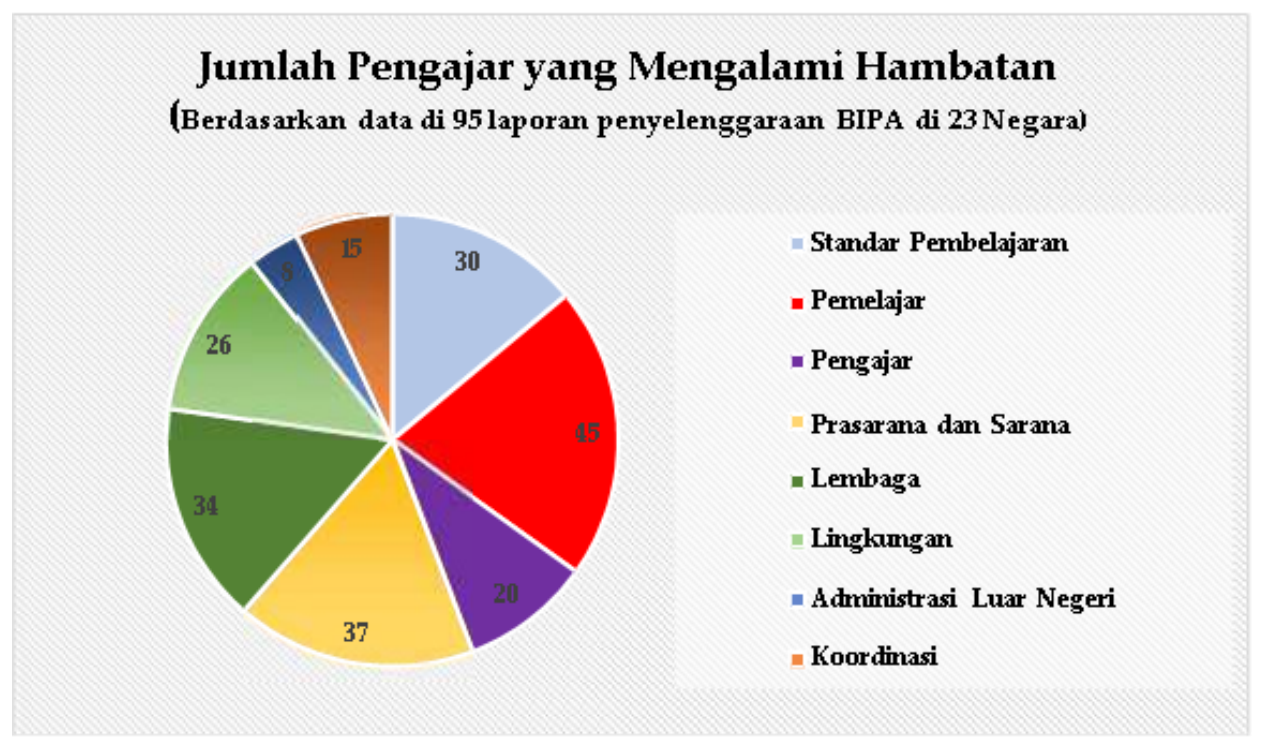

Gambar 1. Jumlah Pengajar yang Mengalami Hambatan di 23 Negara

Gambar 1 menunjukkan bahwa hambatan yang paling banyak dialami, baik oleh pengajar maupun hambatan terkait upaya pengembangan BIPA di luar negeri, berasal dari aspek pemelajar, yaitu sebanyak 45 orang mengalami hambatan tersebut. Hambatan ini terutama berkaitan dengan rendahnya tingkat kehadiran pemelajar, rendahnya minat dan motivasi pemelajar, dan pengaruh dari budaya dan bahasa ibu terhadap pemelajar yang menyebabkan pemelajar kesulitan mempelajari bahasa Indonesia. Adapun hambatan- hambatan tersebut terjadi di negara Thailand, Timor Leste, Mesir, Filipina, Tunisia, Australia, India, Laos, Myanmar, Papua Nugini, Amerika Serikat, Finlandia, Italia, Jepang, Kamboja, Prancis, dan Uzbekistan.

Hambatan berikutnya terjadi pada aspek prasarana dan sarana di luar negeri. Gambar di atas menunjukkan bahwa 37 pengajar mengalami hambatan tersebut. Hambatan ini terutama berkaitan dengan belum memadainya ruang kelas, media pembelajaran, jaringan internet, dan listrik. Adapun hambatan tersebut terjadi di Australia, Filipina, India, Italia, Jerman, Kamboja, Mesir, Papua Nugini, Prancis, Rusia, Thailand, Timor Leste, Tunisia, dan Uzbekistan.

Hambatan berikutnya terjadi pada aspek lembaga sasaran. Gambar di atas menunjukkan bahwa 34 pengajar mengalami hambatan tersebut. Hambatan ini terutama berkaitan dengan belum dijadikannya bahasa Indonesia sebagai program studi/mata kuliah wajib, kurang terjangkaunya lokasi lembaga, adanya pembatasan jumlah pemelajar BIPA oleh lembaga sasaran, jadwal kelas bahasa Indonesia yang bersamaan dengan mata pelajaran lain, dan tidak adanya sanksi terkait ketidakhadiran pemelajar. Adapun hambatan tersebut terjadi di Australia, Filipina, Finlandia, India, Inggris, Jerman, Mesir, Papua Nugini, Prancis, Rusia, Thailand, Timor Leste, dan Tunisia.

Hambatan berikutnya terjadi pada aspek standar pembelajaran. Gambar di atas menunjukkan bahwa tiga puluh pengajar mengalami hambatan tersebut. Hambatan ini terutama berkaitan dengan kurikulum dan silabus BIPA, materi pada buku Sahabatku Indonesia, jumlah pengajar BIPA, dan alokasi waktu. Adapun hambatan tersebut terjadi di Australia, Filipina, Finlandia, India, Inggris, Jerman, Mesir, Papua Nugini, Prancis, Rusia, Thailand, Timor Leste, dan Tunisia.

Hambatan berikutnya terjadi pada aspek lingkungan. Gambar di atas menunjukkan bahwa 26 pengajar mengalami hambatan tersebut. Hambatan ini terutama berkaitan dengan perubahan cuaca, tidak tersedianya tempat tinggal di sekitar lembaga, biaya hidup, transportasi umum, dan konflik atau bencana. Adapun hambatan tersebut terjadi di Amerika Serikat, Australia, 
Finlandia, India, Inggris, Mesir, Papua Nugini, Prancis, Thailand, Timor Leste, Tunisia, dan Uzbekistan.

Hambatan berikutnya terjadi pada aspek koordinasi antarlembaga. Gambar di atas menunjukkan bahwa 15 pengajar mengalami hambatan tersebut. Hambatan ini terutama berkaitan dengan sosialisasi, kerjasama, dan monitoring evaluasi program BIPA di luar negeri, serta waktu keberangkatan/penugasan pengajar. Adapun hambatan tersebut terjadi di Amerika Serikat, Filipina, India, Malaysia, Myanmar, Prancis, Thailand, Timor Leste, dan Uzbekistan.

Hambatan berikutnya terjadi pada aspek administrasi luar negeri. Gambar di atas menunjukkan bahwa 8 pengajar mengalami hambatan tersebut. Hambatan ini terutama berkaitan dengan proses pembuatan dan perpanjangan izin tinggal/visa. Adapun hambatan tersebut terjadi di Amerika Serikat, Filipina, India, Malaysia, Myanmar, Prancis, Thailand, Timor Leste, dan Uzbekistan.

Berikut adalah penjelasan secara rinci mengenai hambatan yang dialami oleh pengajar dan hambatan dalam upaya pengembangan BIPA di setiap negara.

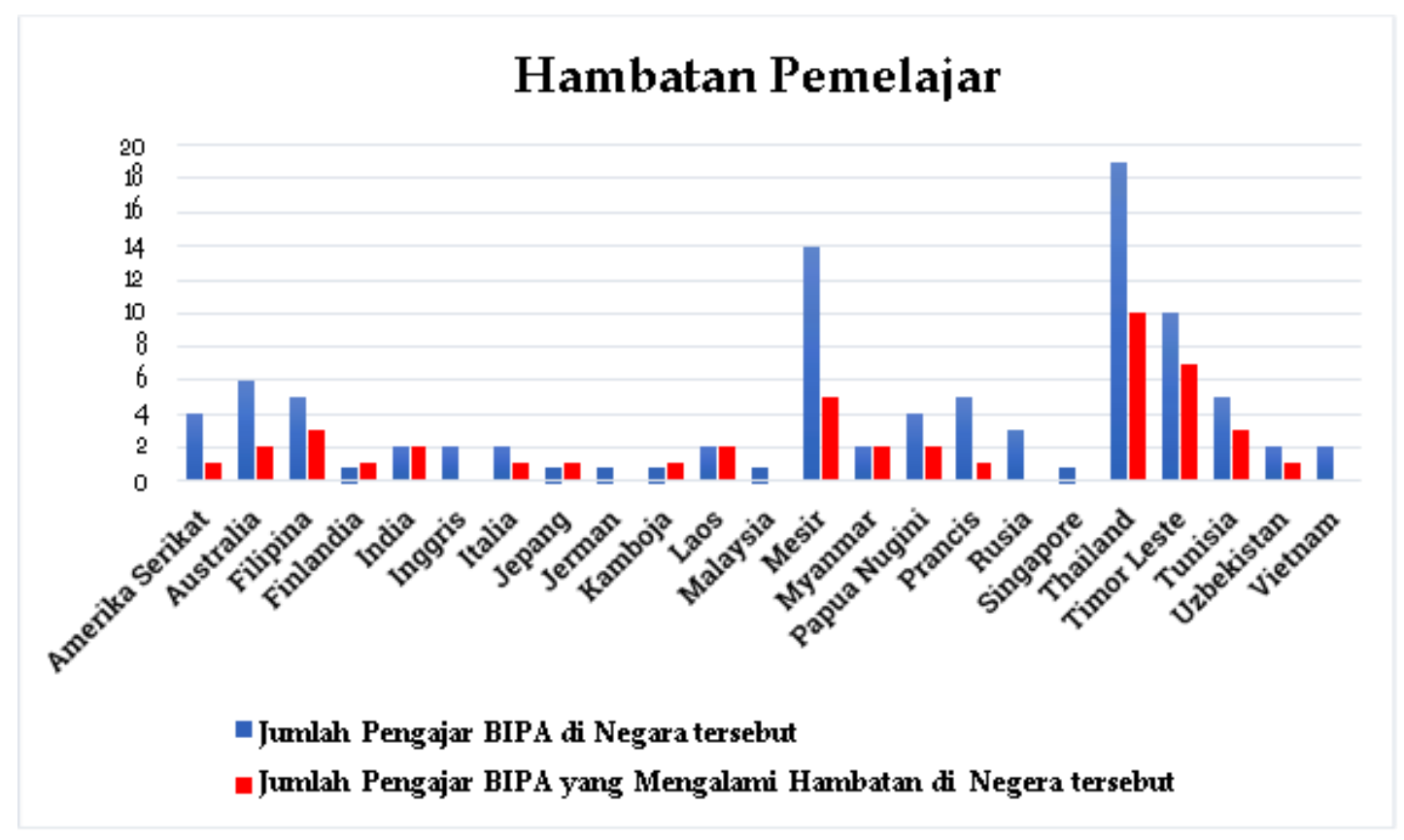

Gambar 2. Hambatan Pemelajar

Gambar 2 menunjukkan hambatan dari aspek pemelajar, yaitu tingkat kehadiran, minat, dan motivasi pemelajar yang masih rendah, serta pemelajar masih terpengaruh bahasa ibu dalam mempelajari bahasa Indonesia. Adapun hambatan tersebut terjadi di Amerika Serikat, Australia, Filipina, Finlandia, India, Italia, Jepang, Kamboja, Laos, Mesir, Myanmar, Papua Nugini, Prancis, Thailand, Timor Leste, Tunisia, dan Uzbekistan. 


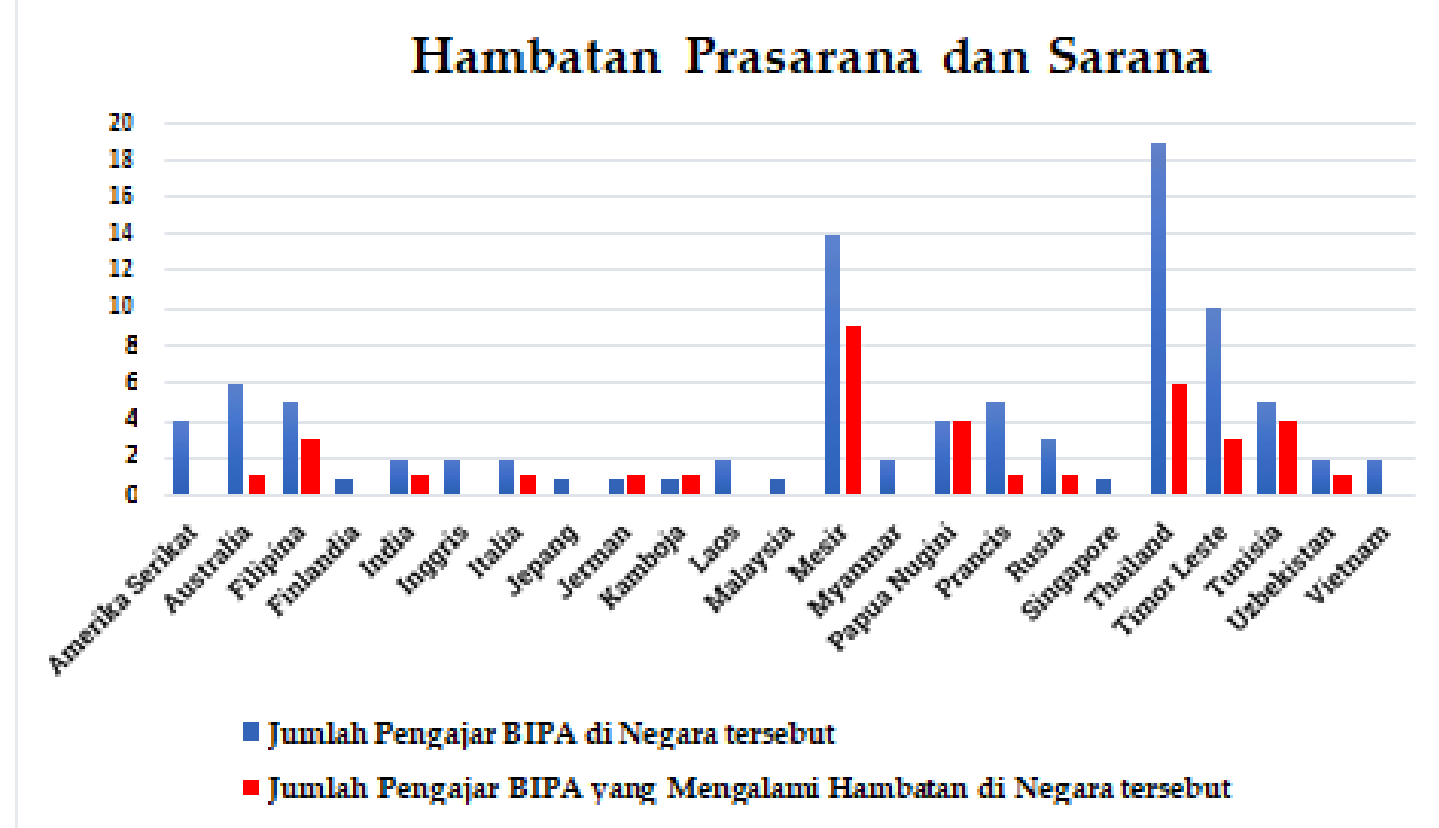

Gambar 3. Hambatan Prasaran dan Sarana

Gambar 3 menunjukkan hambatan dari aspek prasarana dan sarana, yaitu ruang kelas yang digunakan belum memadai, media pembelajaran belum memadai, jaringan internet yang kurang memadai, dan listrik yang kurang memadai. Adapun hambatan-hambatan tersebut terjadi di negara Mesir, Thailand, Papua Nugini, Tunisia, Filipina, Timor Leste, Australia, India, Italia, Jerman, Kamboja, Prancis, Rusia, dan Uzbekistan.

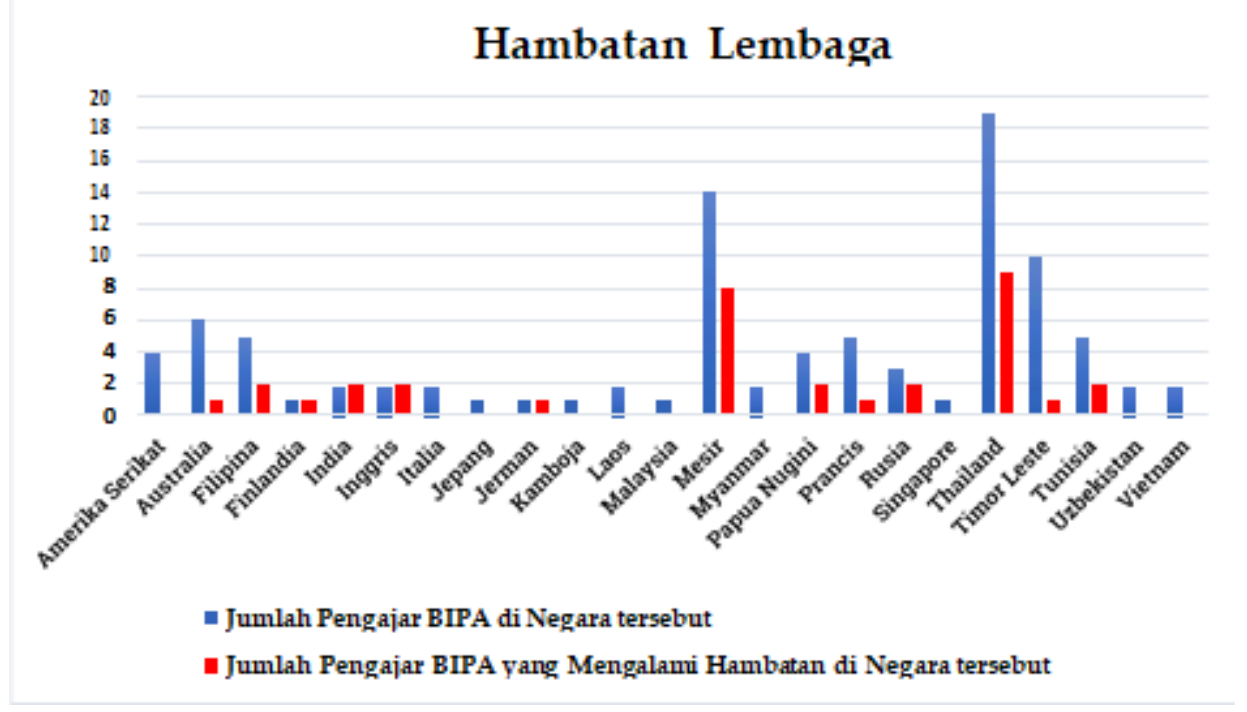

Gambar 4. Hambatan Lembaga

Gambar 4 menunjukkan hambatan dari aspek lembaga, yaitu bahasa Indonesia belum menjadi program studi/mata pelajaran wajib, lokasi lembaga tidak mudah dijangkau, pembatasan jumlah pemelajar BIPA oleh lembaga sasaran, jadwal kelas Bahasa Indonesia bersamaan dengan mata pelajaran/mata kuliah lain, dan tidak ada sanksi terkait ketidakhadiran pemelajar. 
Adapun hambatan-hambatan tersebut terjadi di negara Thailand, Mesir, Filipina, India, Inggris, Papua Nugini, Rusia, Tunisia, Australia, Finlandia, Jerman, Prancis, dan Timor Leste.

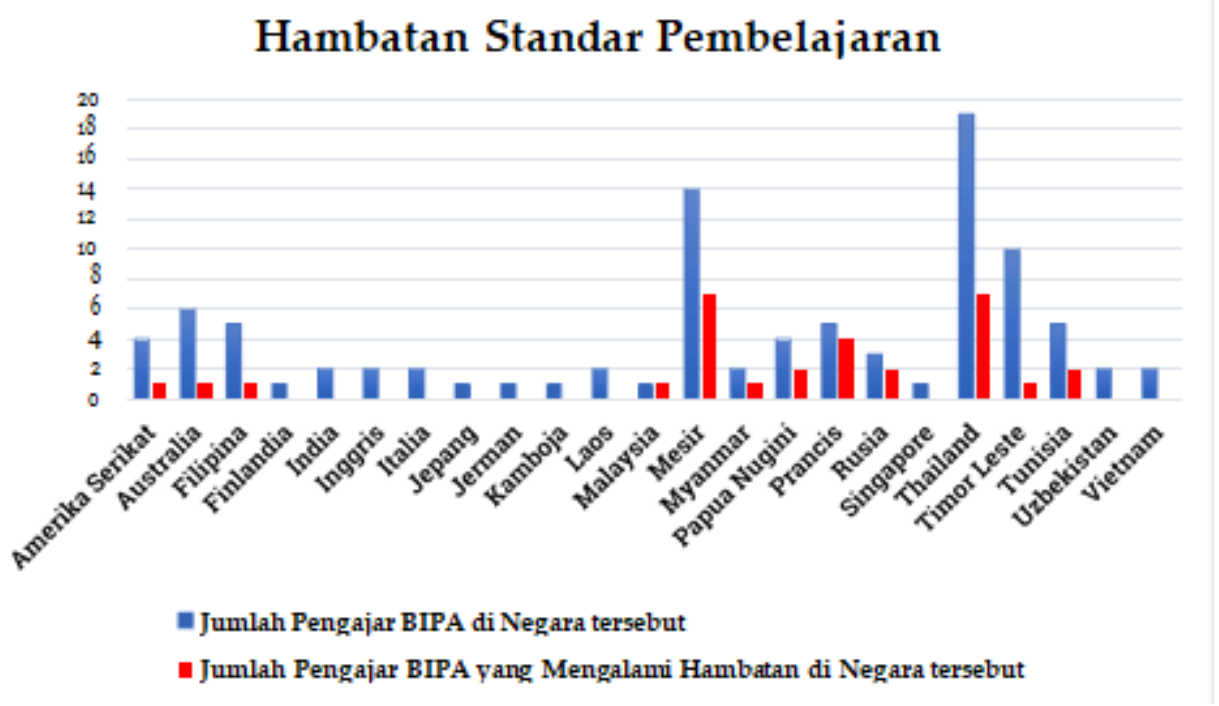

Gambar 5. Hambatan Standar Pembelajaran

Gambar 5 menunjukkan hambatan dari aspek standar pembelajaran, yaitu kurikulum dan silabus BIPA belum sesuai SKL, materi buku Sahabatku Indonesia belum sesuai dengan karakteristik dan kebutuhan pemelajar, jumlah buku penunjang pembelajaran belum memadai, jumlah pengajar BIPA belum sebanding dengan jumlah pemelajar, dan alokasi waktu pemelajar belum sesuai dengan SKL. Adapun hambatan standar pembelajaran terjadi di Amerika Serikat, Australia, Filipina, Malaysia, Mesir, Myanmar, Papua Nugini, Prancis, Rusia, Thailand, Timor Leste, dan Tunisia.

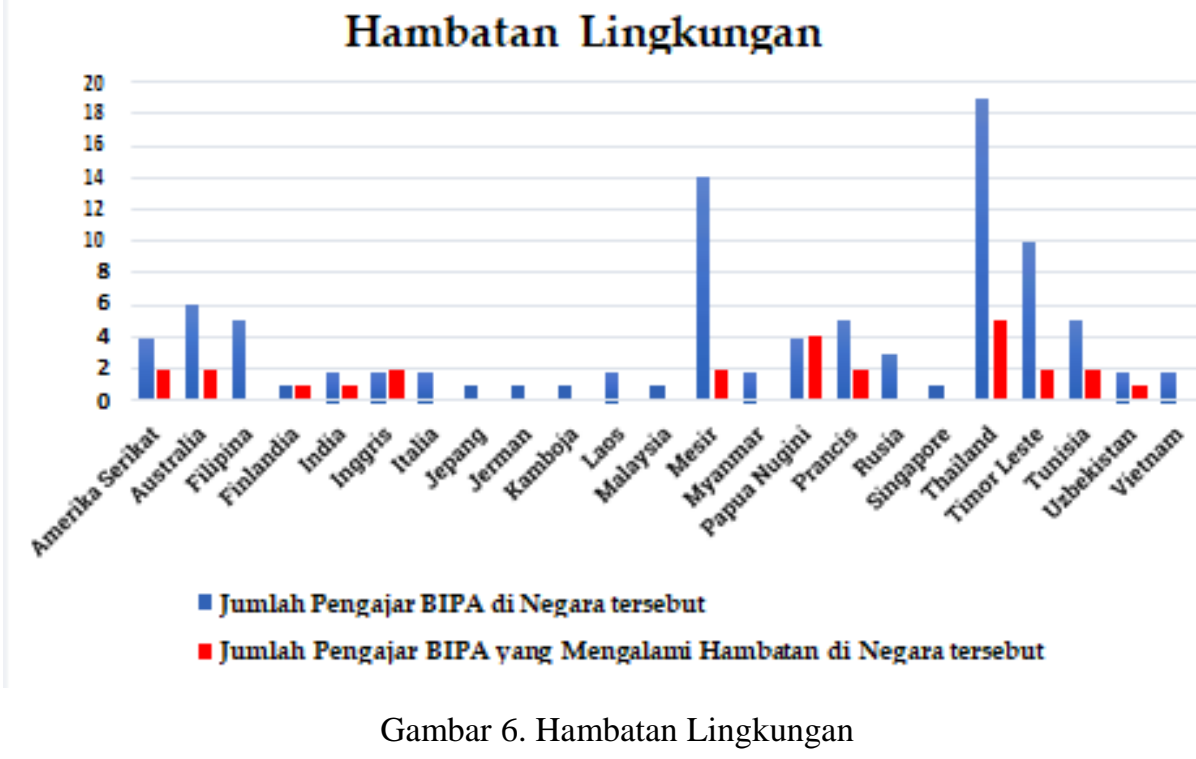

Gambar 6 menunjukkan hambatan dari aspek lingkungan, yaitu perubahan kondisi cuaca yang ekstrem, tempat tinggal jauh dari lembaga, biaya hidup relatif tinggi, tempat 
tinggal tidak kondusif, transportasi umum terbatas, ada konflik atau bencana daerah, dan toleransi beragama masih rendah. Adapun hambatan-hambatan tersebut terjadi di negara Thailand, Papua Nugini, Amerika Serikat, Australia, Inggris, Mesir, Prancis, Timor Leste, Tunisia, Finlandia, India, dan Uzbekistan.

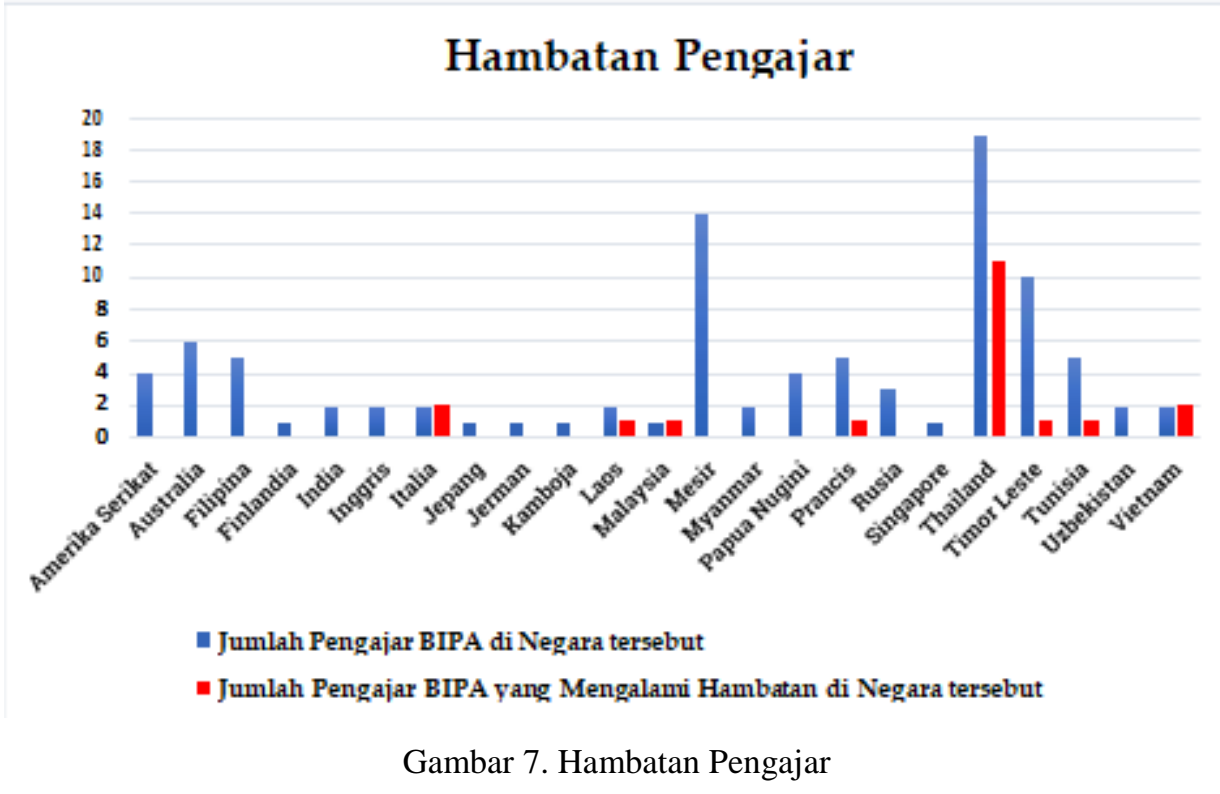

Gambar 7 menunjukkan hambatan dari aspek pengajar, yaitu pengajar belum menguasai bahasa negara penugasan. Adapun hal yang meliputi hambatan pada aspek pengajar, adalah pengajar belum menguasai bahasa lokal. Hambatan tersebut terjadi di negara Thailand, Italia, Vietnam, Laos, Malaysia, Prancis, Timor Leste, dan Tunisia.

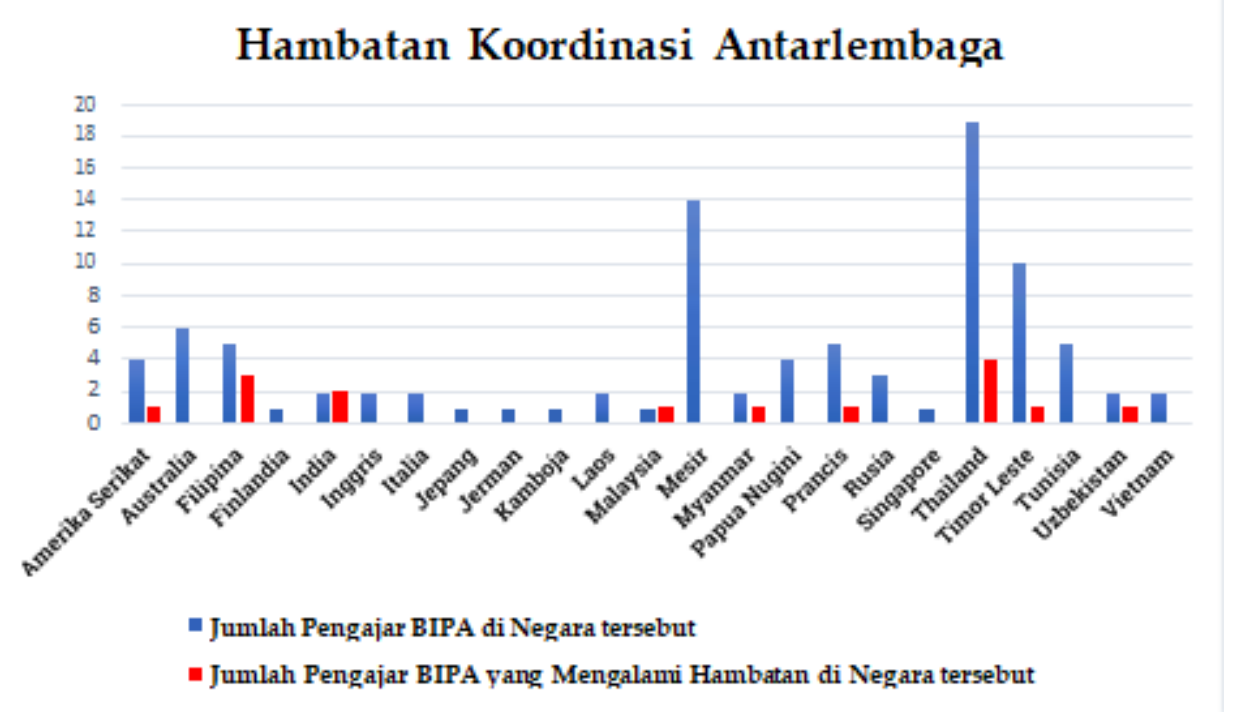

Gambar 8. Hambatan Koordinasi Antarlembaga

Gambar 8 menunjukkan hambatan dari aspek koordinasi antarlembaga, yaitu belum optimalnya sosialisasi, kerjasama, dan monitoring evaluasi program BIPA di luar negeri serta waktu pemberangkatan/penugasan pengajar sesuai kalender akademik. Hambatan-hambatan 
tersebut terjadi di negara Thailand, Filipina, India, Amerika Serikat, Malaysia, Myanmar, Prancis, Timor Leste, dan Uzbekistan.

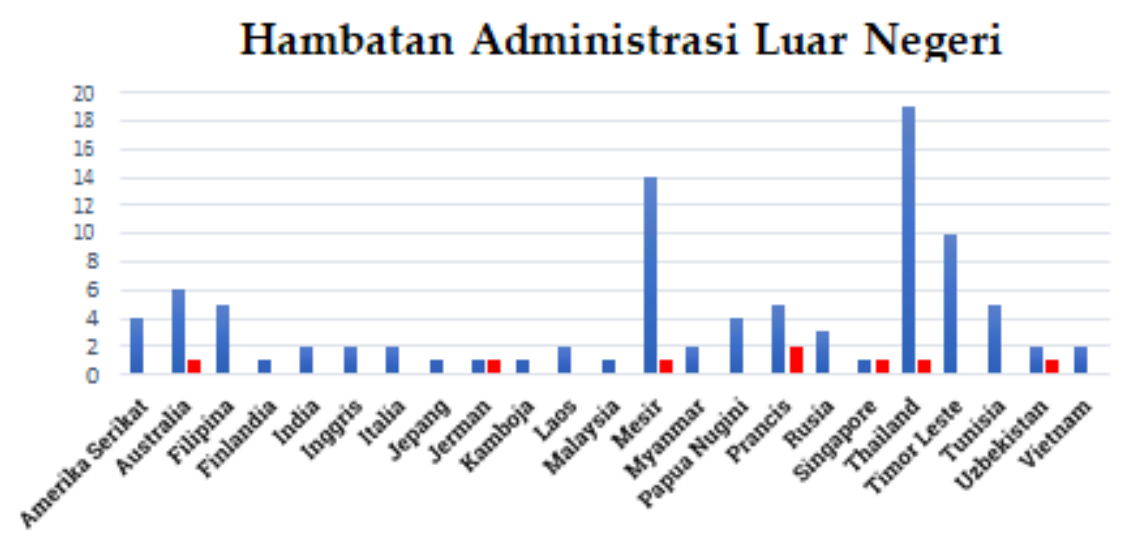

Gambar 9. Hambatan Administrasi Luar Negeri

Gambar 9 menunjukkan hambatan dari aspek administrasi luar negeri, yaitu sulitnya perpanjangan visa/izin tinggal dan sulitnya proses pembuatan kartu izin tinggal. Adapun hambatan-hambatan tersebut terjadi di negara Prancis, Australia, Jerman, Mesir, Singapura, Thailand, dan Uzbekistan.

\section{Simpulan}

Dalam penelitian ini telah dipetakan dan dianalisis jenis-jenis hambatan di setiap negara yang dialami para pengajar BIPA yang di tugaskan ke 23 negara. Hal ini untuk memudahkan identifikasi dan menentukan jenis hambatannya. Adapun hambatan-hambatan tersebut terbagi ke dalam delapan aspek hambatan secara umum yang terdapat di dalam 23 negara, yaitu hambatan standar pembelajaran, hambatan pemelajar, hambatan pengajar, hambatan prasarana dan sarana, hambatan lembaga sasaran, hambatan lingkungan di luar negeri, hambatan administrasi luar negeri, dan hambatan koordinasi antarlembaga.

Pada aspek standar pembelajaran, diperoleh data yang menunjukkan bahwa hambatan terjadi di Amerika Serikat, Australia, Filipina, Malaysia, Mesir, Myanmar, Papua Nugini, Prancis, Rusia, Thailand, Timor Leste, dan Tunisia. Hambatan pada aspek ini berkaitan dengan kurikulum dan silabus BIPA belum sesuai SKL, materi buku Sahabatku Indonesia belum sesuai dengan karakteristik dan kebutuhan pemelajar, jumlah buku penunjang pembelajaran belum memadai, jumlah pengajar BIPA belum sebanding dengan jumlah pemelajar, dan alokasi waktu pemelajar belum sesuai dengan SKL.

Pada aspek pemelajar, diperoleh data yang menunjukkan bahwa hambatan terjadi di Amerika Serikat, Australia, Filipina, Finlandia, India, Italia, Jepang, Kamboja, Laos, Mesir, Myanmar, Papua Nugini, Prancis, Thailand, Timor Leste, Tunisia, dan Uzbekistan. Hambatan yang terjadi pada aspek ini berkaitan dengan tingkat kehadiran pemelajar, minat dan motivasi pemelajar, dan pengaruh bahasa ibu dalam pembelajaran bahasa Indonesia.

Pada aspek pengajar, diperoleh data yang menunjukkan bahwa hambatan terjadi di Thailand, Italia, Vietnam, Laos, Malaysia, Pancis, Timor Leste, dan Tunisia. Hambatan yang terjadi pada aspek ini berkaitan dengan penguasaan bahasa negara penugasan.

Pada aspek prasarana dan sarana, diperoleh data yang menunjukkan bahwa hambatan terjadi di Mesir, Thailand, Papua Nugini, Tunisia, Filipina, Timor Leste, Australia, India, Italia, Jerman, Kamboja, Prancis, Rusia, dan Uzbekistan. Hambatan pada aspek ini berkaitan dengan 
ketersediaan ruang kelas, media pembelajaran, jaringan internet, dan listrik di lembaga tempat mengajar BIPA.

Sementara itu pada aspek lembaga sasaran, diperoleh data yang menunjukkan bahwa hambatan terjadi Thailand, Mesir, Filipina, India, Inggris, Papua Nugini, Rusia, Tunisia, Australia, Finlandia, Jerman, Prancis, dan Timor Leste. Hambatan pada aspek ini berkaitan dengan bahasa Indonesia sebagai mata kuliah/mata pelajaran wajib, lokasi tempat mengajar BIPA, batas jumlah pemelajar BIPA, jadwal kelas bahasa Indonesia, dan sanksi terkait ketidakhadiran pemelajar.

Adapun pada aspek lingkungan di luar negeri, diperoleh data yang menunjukkan bahwa hambatan terjadi di Thailand, Papua Nugini, Amerika Serikat, Australia, Inggris, Mesir, Prancis, Timor Leste, Tunisia, Findlandia, India, dan Uzbekistan. Hambatan pada aspek ini berkaitan dengan perubahan kondisi cuaca, tempat tinggal pengajar, biaya hidup, kondusifitas lingkungan tempat tinggal, akses transportasi umum, dan konflik atau bencana daerah.

Kemudian pada aspek administrasi luar negeri, diperoleh data yang menunjukkan bahwa hambatan terjadi di Prancis, Australia, Jerman, Mesir, Singapura, Thailand, dan Uzbekistan. Hambatan pada aspek ini berkaitan dengan kemudahan proses pembuatan dan perpanjangan visa/izin tinggal.

Terakhir pada aspek koordinasi antarlembaga, diperoleh data yang menunjukkan bahwa hambatan terjadi di Thailand, Filipina, India, Amerika Serikat, Malaysia, Myanmar, Prancis, Timor Leste, dan Uzbekistan. Hambatan pada aspek ini berkaitan dengan sosialisasi, kerjasama, monitoring evaluasi program BIPA, danwaktu pemberangkatan/penugasan pengajar.

\section{Daftar Rujukan}

Damshauser, B. (2017). Dialog Sunyi: Bahasa dan Sastra Indonesia dalam Konteks Global. Prosiding Seminar Nasional Bahasa dan Sastra Indonesia dalam Konteks Global (xi-xix). Jember: Prodi Pendidikan Bahasa dan Sastra Indonesia Fakultas Keguruan dan Ilmu Pendidikan Universitas Jember.

Maguire, M. \& Delahunt, B. (2017). Doing a Thematic Analysis: A Practical, Step-by-Step Guide for Learning and Teaching Scholars. All Ireland Journal of Teaching and Learning in Higher Education (AISHE-J). 8(3): 3351--33514

Peraturan Menteri Pendidikan dan Kebudayaan Nomor 11 Tahun 2015 tentang Organisasi dan Tata Kerja Kementerian Pendidikan dan Kebudayaan.

Peraturan Pemerintah Nomor 57 Tahun 2014 tentang Pengembangan, Pembinaan, dan Pelindungan Bahasa dan Sastra, serta Peningkatan Fungsi Bahasa Indonesia.

Phillipson, R. (2008). Linguistic Imperialism. Oxford: Oxford University Press.

Rencana Strategis Pusat Pengembangan Strategi dan Diplomasi Kebahasaan tahun 2015-2019.

Sugiyono. (2010). Memahami Penelitian Kualitatif. Bandung: Alfabeta.

Sugono, D. (2017). Bahasa Indonesia Menuju Bahasa Internasional. Jurnal FON, 9(1): 399-404.

Undang-Undang Nomor 24 Tahun 2009 tentang Bendera, Bahasa, dan Lambang Negara, serta Lagu Kebangsaan. 